\title{
A REPRESENTATIVIDADE DOS INSTITUTOS FEDERAIS NO VII CONGRESSO LATINO-AMERICANO DE FORMAÇÃO DE PROFESSORES DE LÍNGUAS ${ }^{1}$
}

\section{REPRESENTATIVENESS OF FEDERAL INSTITUTES IN THE VII LATIN-AMERICAN CONGRESS ON LANGUAGE TEACHER EDUCATION}

\author{
Aline Moraes de Carvalho* \\ Mônica Bomtempo Reis Soares**
}

\begin{abstract}
Resumo: Através de uma metassíntese qualitativa (ALENCAR \& ALMOULOUD, 2017) dos estudos apresentados no VII Congresso Latino-americano de Formação de Professores de Línguas (CLAFPL) que tinham como contexto os Institutos Federais (IFs) ou que tivessem sido produzidos por docentes dessas instituições, tentamos identificar a formação acadêmica dos professores-pesquisadores, as tendências, recorrências e lacunas tanto nos trabalhos produzidos pelos IFs quanto aqueles produzidos sobre o ensino de línguas nos IFs. Observamos o desenvolvimento de uma identidade de professorpesquisador na área da Linguística Aplicada, que pode ser percebida na participação dos docentes no evento, com trabalhos que abrangeram a maioria dos eixos temáticos existentes.
\end{abstract}

Palavras-chave: Pesquisa. Docente. Institutos Federais. Línguas.

Abstract: Through a qualitative metasynthesis (ALENCAR \& ALMOULOUD, 2017) of the studies presented at VII CLAFPL - Latin-American Congress on Language Teacher Education that had federal institutes -IFs as context or were produced by teacher-researchers working in IFs, in an attempt to identify teacher-researchers' academic background, trends, recurrences, and gaps in both the works produced by IFs and about language teaching in this context. We observed the development of a teacherresearch identity in the field of applied linguistics, which can be noticed through their participation in the event and the works presented there, which covered most of the themes established for that event.

Keywords: Research. Teacher. Federal Institutes. Languages.

\section{Introdução}

Vivemos em um mundo onde a racionalidade técnica domina em quase todas as áreas, inclusive na educação (GARIGLIO \& BURNIER, 2014). No Brasil, onde o modelo socioeconômico culmina na concentração de riqueza e na precarização do emprego, a educação é uma possibilidade de reverter/lutar contra o sistema opressor de classes (FREIRE, 1996).

A exemplo da Educação Profissional e Tecnológica (EPT), para Moura (2008, p. 28), esta tem o poder de "contribuir com o aumento da capacidade de (re) inserção social, laboral e política dos seus formados", na medida em que propõe preparar o sujeito para o exercício profissional através de cursos em nível de qualificação, habilitação técnica, tecnologia e pós-graduação (BRASIL, 2020a). Assim, ao pensarmos na educação como caminho para a emancipação do sujeito, como já pregava Freire em

\footnotetext{
${ }^{1}$ Este trabalho é um recorte da pesquisa realizada no curso de Especialização em Docência na Educação Profissional e Tecnológica, no Instituto Federal do Sudeste de Minas Gerais.

* Mestre em Estudos Linguísticos, Universidade Federal de Viçosa, alinecarvalho.tur@gmail.com.

** Mestre em Educação, IF Sudeste MG Campus Rio Pomba, monica.bomtempo@ifsudestemg.edu.br.
} 
seu livro Pedagogia da Autonomia (1996), precisamos considerar um dos principais atores envolvidos no processo, o docente. Podendo o professor contribuir para o processo de transformação social, conscientizando a sociedade (MOURA, 2008), faz-se necessária uma formação docente que seja crítica, ultrapassando a educação bancária. E, para tal, a formação do professor é de suma importância para que este objetivo seja cumprido, especialmente no caso da EPT.

Em trabalhos sobre os saberes, identidades e formação docente na EPT (GARIGLIO \& BURNIER, 2014; SANTIAGO, 2014), percebemos a escassez de informações sobre esse grupo. Segundo esses pesquisadores, grande parte dos professores que atuam na EPT tem apenas a formação técnica na área, como uma prática embasada em modelos tradicionais pré-estabelecidos social e culturalmente, com foco no mercado. Gariglio e Burnier (2014) apontam a valorização dos saberes provenientes do mercado em detrimento ao didático- pedagógico, e lembram que o conhecimento técnico ou domínio do conteúdo não bastam para o ensino, é preciso saber ensinar - o que implica em ter conhecimento para fazê-lo nas mais variadas formas, considerando as especificidades dos alunos e do contexto em que se encontram inseridos. Tanto Gariglio e Burnier (2014) quanto Santiago (2014) reafirmam a necessidade de se romper com tais modelos, através de uma formação pedagógica sólida para docentes pesquisadorescrítico-reflexivos, se quisermos promover a mudança na sociedade.

São muitos os trabalhos científicos que têm discutido a questão da formação dos profissionais docentes para e na EPT. Encontramos entre eles, inclusive, um apanhado histórico da legislação que concerne tanto a criação e ampliação dos cursos técnicos e profissionalizantes, quanto a obrigatoriedade ou não da formação específica para atuação de profissionais nesta modalidade de ensino (ANDRADE \& SOUZA, 2015; JUNIOR, 2009).

Moura (2008) e Santiago (2014), porém, apontam a escassez de estudos sobre o perfil e identidade dos docentes que atuam na EPT bem como os desafios que permeiam sua prática. A docência na EPT em si também ainda é pouco investigada no Brasil, segundo Pena (2016). Após levantamento de eventos que ocorreram na última década no Brasil, em especial os ligados à Associação Nacional de Pós-graduação e Pesquisa em Educação (ANPEd), Pena (2016) comprova tal escassez, e ainda afirma que há falta de diálogo entre as pesquisas de formação de professores em geral e a formação de professores para a EPT, seja ela inicial ou continuada.

Após participação no VII Congresso Latino-americano de Formação de Professores de Línguas (CLAFPL), observamos um número considerável de participantes identificados como atuantes no âmbito dos Institutos Federais (IFs), diferente do observado por nós em outros eventos no campo da Linguística Aplicada (LA). Após assistirmos algumas apresentações de docentes lotados nos IFs, ficamos intrigados sobre quais os tipos de investigações têm sido feitas nesse contexto. E, também, qual seria o motivo da participação desses professores neste congresso ao invés de em outros eventos diretamente relacionados ao contexto dos IFs.

Assim, pretendemos aqui levantar os trabalhos científicos apresentados por docentes dos IFs e também os produzidos tendo tais instituições como contexto, identificando os principais campos de estudo em que se concentraram as pesquisas, na tentativa de compreender e elaborar um possível perfil destes como professorespesquisadores. 
Além da escassez de estudos na área, esta proposta se justifica em três níveis, como proposto por André (2005): científico, social e pessoal. Como já apontado anteriormente, a presente pesquisa corrobora os estudos no campo da docência na EPT, $\mathrm{e}$, consequentemente, na medida em que nos permite conhecer os desafios e propostas do docente pesquisador, possibilita a ação para a mudança, que pode levar ao aumento da qualidade do ensino e melhoria da formação e fazer docente. Tem importância social, cultural e política, pois como posto por Moura (2014, p. 104), "é preciso conhecer melhor a realidade das instituições para atuar de forma mais sistêmica na educação brasileira". Além disso, o foco no docente das disciplinas de línguas estrangeiras e materna é de especial interesse para a primeira autora do presente trabalho dado sua formação, que pretende melhor compreender a atuação do docente destas disciplinas na EPT a fim de preparar-se para seu futuro profissional.

Este artigo está organizado em quatro seções. Na primeira, discutimos brevemente sobre o professor da EPT no Brasil, para então nos concentrarmos no professor pesquisador e sujeito pesquisado. $\mathrm{Na}$ segunda, discorremos sobre a metodologia, explicando a natureza do trabalho, o contexto e o processo de coleta e análise de dados. Na terceira, apresentamos e discutimos os resultados. E, por último, concluímos o texto com sugestões para pesquisas futuras.

\section{Referencial teórico}

\subsection{A formação do professor da EPT no Brasil}

Prevista na Lei de Diretrizes e Bases da Educação Nacional (LDB), a Educação Profissional e Tecnológica (EPT) é uma modalidade educacional que visa formar e preparar o cidadão para o exercício de uma profissão - auxiliando sua atuação no mercado e na vida em sociedade - através da oferta de cursos de qualificação, habilitação técnica e tecnológica, e de pós-graduação (BRASIL, 2020a). Revista pela Lei

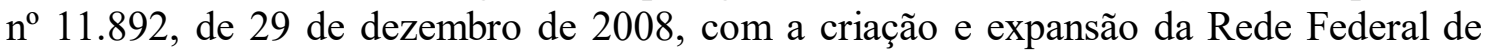
Educação Profissional, Científica e Tecnológica, a EPT é ofertada majoritariamente através de 38 Institutos Federais, dois Centros Federais de Educação Tecnológica (Cefet), a Universidade Tecnológica Federal do Paraná (UTFPR), 22 escolas técnicas vinculadas às universidades federais e o Colégio Pedro II, contando com um total 661 unidades/campi associados, segundo o Ministério da Educação (BRASIL, 2020b), distribuídos nas 27 unidades federativas (Fig.1). 
Figura 1 - Distribuição geográfica dos Institutos Federais

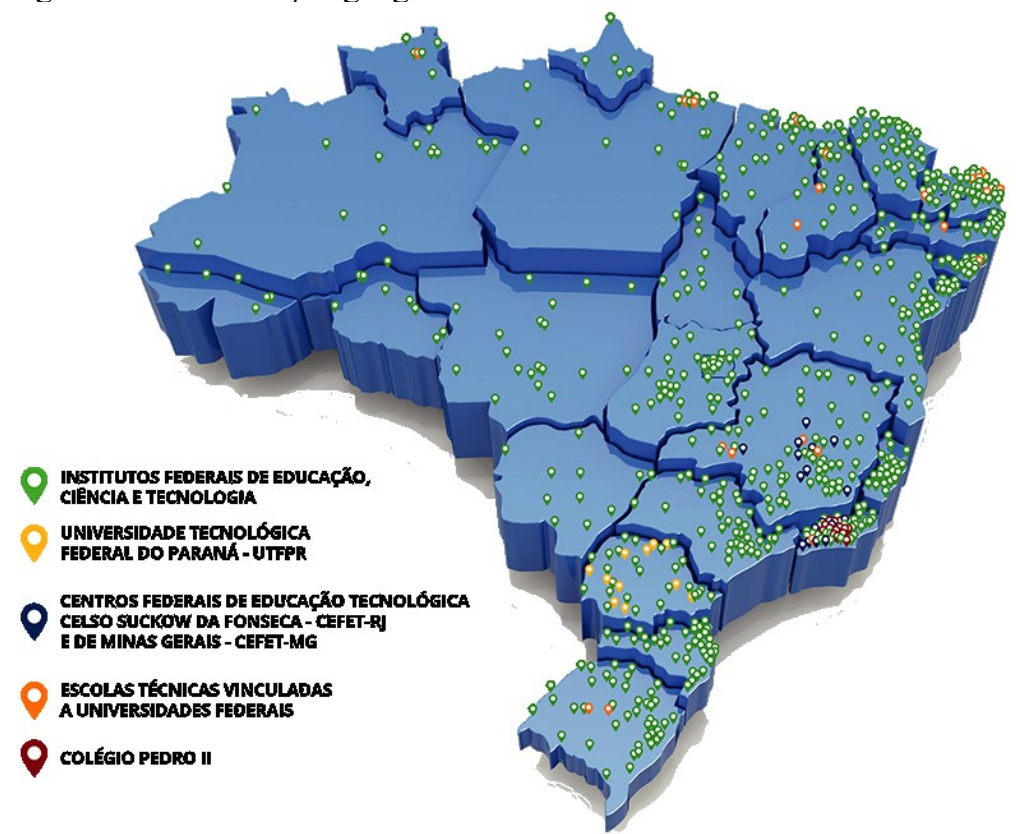

Fonte: http://portal.mec.gov.br/rede-federal-inicial/instituicoes

Apesar da expansão da rede federal, pouco ou quase nada se fala sobre seus docentes, seja na LDB de 2006 ou na Lei de 2008. Um estudo realizado pela Coordenação de Aperfeiçoamento de Pessoal de Nível Superior (CAPES) revelou que muitos professores do ensino fundamental e médio da rede pública assumem disciplinas para as quais não tiveram formação específica; e que apenas $28 \%$ do total de graduados em licenciaturas lecionam na área em que formaram, sendo o caso mais grave no norte e nordeste, onde essa porcentagem aumenta para $69 \%$ e $67,5 \%$, respectivamente (GIMENEZ, 2013).

Se no ensino regular tínhamos por volta de 477 mil professores - segundo Censo de 2010, apresentado no trabalho de Moura (2014), a quantidade de docentes na EPT é consideravelmente menor, pouco mais de 62 mil. Em 2013, os dados da Sinopse Estatística da Educação Básica revelaram que de um total de 73.904 professores da EPT (englobando as esferas federal, estadual, municipal e privada), 65.718 possuem curso superior, mas apenas 18.659 com licenciatura (PENA, 2016). Ainda, segundo relatório de auditoria apresentado em 2013 ao Tribunal de Contas da União (TCU), 73\% dos professores da EPT não possuem licenciatura ou formação pedagógica (BRASIL, 2013).

Contudo, de acordo com Santiago (2014), se por um lado a maioria dos professores da EPT não possui formação pedagógica, por outro, os licenciados apontam que sua formação não dá conta das especificidades do contexto da EPT. Moura (2014) afirma que só se deve ensinar aquilo que se domina em profundidade, ou seja, que se tenha competência técnica na área, mas explica que só isso não basta. Para o autor, é preciso que os docentes licenciados em disciplinas referentes à educação propedêutica tenham também uma formação continuada específica para a educação profissional, enquanto os não licenciados devam investir em sua formação pedagógica. Assim, ainda segundo Moura (2014), a pós-graduação lato sensu seria a mais adequada, pois aproxima os docentes das disciplinas de formação profissional aos saberes de sua área de 
conhecimento específica e dos saberes pedagógicos característicos desse contexto de ensino.

Como a oferta de formação continuada formal não acontece na maioria das instituições, alguns professores buscam no mestrado e doutorado uma forma de enriquecer sua prática pedagógica (SANTIAGO, 2014). Mas, segundo a autora, apesar da titulação e produção científica ajudarem na progressão na carreira, elas nem sempre garantem um ensino de qualidade, o que não pode ser justificativa para a não procura por formação continuada, que a nosso ver se dá tanto informal como formalmente, através da prática diária reflexiva, do estudo, de cursos, da pesquisa e da troca de experiências entre outros docentes.

Apesar da importância da qualificação, tanto na formação inicial quanto na continuada, o que se nota no Brasil é uma política que Oliveira (2005 apud GARIGLIO \& BURNIER, 2012) chama de "política de não formação" destinada aos professores que atuam no âmbito da EPT, que culmina na visão de professores que não se veem como pertencentes à área da educação efetivamente, mas profissionais do mercado que tem a docência como atuação no momento. Essa percepção tem se reforçado com a carência de estudos sobre tal tema, e também por certa "desmobilização da categoria em torno dessa questão" (GARIGLIO \& BURNIER, 2012, p. 213).

Não muito diferente da formação do profissional docente, o trabalhador, durante séculos, tem sido expropriado do conhecimento que circunda seu ofício, repetindo práticas previamente impostas. Por vezes, sem saber sobre o propósito ou o produto do processo do qual ele faz parte, não consegue perceber sua importância nessa engrenagem (MOURA, 2014). Contudo, se domina o conteúdo do próprio trabalho, teorias que embasam e a prática crítica, se intelectualiza e se coloca como um risco à hegemonia, uma possibilidade de transformação, dono da própria ação, percebe o poder do seu fazer.

Miller (2013, p. 101) já nota, porém, um caminhar "da noção de treinamento em direção às noções de educação, formação, trabalho e desenvolvimento profissional em direção à criticidade e ética". Assim, é importante para a manutenção e desenvolvimento da educação e dos IFs que o docente da EPT se perceba como pertencente à classe trabalhadora da educação (MOURA, 2014). E, desta forma, desperte a consciência de classe, compreendendo e reforçando seu compromisso ético-social e político com a sociedade e companheiros da educação, apoiando a construção de conhecimento para mais respeito - entre os pares e a sociedade - e práticas mais transformadoras.

Tal consciência, porém, não se constrói só na prática docente da sala de aula, mas na interação - em sala de aula/ambiente escolar e eventos acadêmicos - e reflexão na e sobre a prática docente. Apesar de não haver sido construída uma cultura de produção acadêmico-científica no campo da docência na EPT (GARIGLIO \& BURNIER, 2012), segundo Miller (2013), é preciso fazê-lo através da pesquisa colaborativa, pesquisa ação e prática exploratória, sejam elas realizadas pelo professor pesquisador ou coordenador, com a colaboração, ou não, de outros professores, pesquisadores e alunos.

Em outras palavras, a relevância da formação pedagógica e crítica do professor com vistas a uma prática reflexiva, criativa/criadora e investigativa fica evidente, e deve desmistificar a crença da pesquisa como objeto do fazer de especialistas (SANTIAGO, 2014). Ou seja, seu fazer docente deve ir para além da aplicação de teorias, mas (re) criação e associação de teorias e saberes/práticas, bem como pesquisa e ensino, a fim de contribuir não só para a atuação e formação de outros profissionais da EPT, mas também para o bem da educação (SANTIAGO, 2014). 


\subsection{A contribuição da pesquisa na formação docente}

Acreditamos que é preciso ver a pesquisa como uma forma de educação contínua, que Celani (2002, p. 22) define como "um processo que possibilita o professor educar-se a si mesmo, à medida que caminha em sua tarefa de educação". Ainda segundo a autora, "a reflexão, no contexto educacional, envolve a substituição do conhecimento pedagógico por perguntas que decorrem da prática pedagógica" (CELANI, 2002, p. 26).

Moura (2014) nos lembra da necessidade de potencializarmos a unidade ensino/pesquisa. Para o autor, o professor precisa "aprender, interpretar, analisar, criticar, refletir, buscar soluções e propor alternativas, potencializadas pela investigação e pela responsabilidade social assumida" (MOURA, 2014, p. 98).

O modelo prático reflexivo, segundo Shön (1983 apud SANTIAGO, 2014) tem assumido um papel significativo no processo de formação de professores, na medida em que permite questionar e refletir sobre suas ações e crenças, ou seja, o que eles fazem e porque o fazem. Em outras palavras, estes professores constroem conhecimento, se apropriam dele e se especializam através da prática profissional reflexiva.

No caso do professor da EPT, nota-se uma carência de produções não só sobre sua formação, mas também sobre sua profissionalização (SANTIAGO, 2014), o que enfraquece as "possibilidades de discussões e fomento de políticas que viabilizem processos de sólida e eficaz formação deste profissional para atuar no ensino (SANTIAGO, 2014, p. 8006). A autora ainda nos lembra que o professor da EPT precisa ter consciência sobre como sua atividade laboral repercute na vida dos futuros profissionais, especialmente dos docentes.

$\mathrm{Na}$ LA, consideramos os professores como produtores de conhecimento - seja ele institucionalizado ou não, uma vez que, como posto por Moita Lopes (2006, p. 101), "conhecimento que não considera as vozes daqueles que vivem a prática social não pode dizer nada sobre ela". Assim, a sala de aula se põe como um campo de pesquisa com muito potencial exploratório devido às diversas atividades e situações que a circundam. É preciso entender o que se passa na sala de aula, para então agir sobre ela. E quem melhor que o professor para investigar este espaço? É possível "usar a prática como próprio palco de criação de reflexões teóricas, ou seja, teoria e prática não são coisas diferentes. A teoria é relevante para a prática porque é concebida dentro da prática" (RAJAGOPALAN, 2011 apud MILLER, p. 103).

$\mathrm{Na}$ investigação da prática docente, é preciso considerar os microuniversos que a envolvem (SANTIAGO, 2014), especialmente devido à "impossibilidade de separar o conhecimento de seu contexto e o processo de construção de significados em relação a fatores sociais, econômicos e políticos que moldam a prática social" (MACIEL, 2013, p. 242).

Para Gariglio e Burnier (2012), se quisermos compreender a atuação do docente na EPT, temos que entendê-la primeiro como um ofício feito de saberes, ou seja, construídos naquela esfera, o que impõe um desafio para sua profissionalização. Esta, segundo estes autores, é motivação suficiente para investigar os saberes próprios desse contexto, revelando as singularidades que circundas esse contexto profissional. Lembram ainda que tais saberes são situados, ou seja, construídos de acordo com cada situação particular de trabalho, e vão ganhando sentido e validade à medida que atendem às necessidades deste. 
Ao refletirmos sobre um campo de saber, é preciso considerar "quem" faz pesquisa, e "o que se diz" sobre o assunto, pois, como posto por Archanjo (2011), esses discursos materializados na pesquisa determinarão sua identidade, bem como a imagem de que se tem deste campo de estudo, seus valores e as ideias defendidas, seja para compreendê-lo ou para lutar por mudanças.

Assim, acreditamos que as pesquisas nesse contexto devam ser realizadas principalmente sob a responsabilidade de quem está diretamente envolvido para fazer essa mudança. Moita Lopes (2006) nos fala das "vozes do sul", dos que estão de fora mesmo estando diretamente envolvidos no objeto de estudo, tradicionalmente apagadas na ciência, pois tem seu conhecimento compreendido como senso comum, não científico ou institucionalizado. Não obstante, este sujeito pode ter uma perspectiva singular da situação, um posicionamento e acesso privilegiados, sendo um dos maiores beneficiados direto dos resultados das pesquisas.

Moita Lopes (2006) discorre, ainda, sobre a importância de se aproximar da teoria a realidade e as práticas, o que, para o trabalho do professor pesquisador pode ser uma grande vantagem. Segundo Bortoni-Ricardo (2008, p. 48), a "grande vantagem do trabalho do professor pesquisador é que ela resulta em uma 'teoria prática', ou seja, em conhecimento que pode influenciar as ações práticas do professor, permitindo uma operacionalização do processo ação-reflexão-ação".

E esse tipo de pesquisa, se bem conduzida e estruturada, pode possibilitar a legitimação do conhecimento local do docente, considerando suas experiências e discussões dos conflitos que emergem das propostas educacionais/institucionais e sua prática através da análise do cotidiano da sala de aula, como proposto por Maciel (2013).

Além disso, na proposta de um professor pesquisador, este não é mero consumidor de teorias que tenta adaptá-las ao seu contexto de trabalho. Pelo contrário, faz uso dos problemas profissionais que o afligem no cotidiano para refletir e produzir conhecimento a fim de melhorar sua prática. Assim, o que o distingue dos demais profissionais, segundo Bortoni-Ricardo (2008, p. 46), é o "compromisso de refletir sobre a própria prática, buscando reforçar e desenvolver aspectos positivos e superar as próprias deficiências".

Desta forma, se espera encontrar um profissional ativo, que

"[...] participe e transforme o ambiente de trabalho ao inserir-se nos processos decisórios da educação como agente político. Nesta perspectiva os professores deverão ser profissionais pesquisadores, autônomos, inovadores. Através da vivência como aluno e professor, dos saberes técnicos iniciais da formação, aliados aos conhecimentos pedagógicos, às práticas profissionais institucionalizadas, às experiências quotidianas e às investigações profissionais; o professor será capaz de produzir conhecimentos durante a carreira profissional, agregando valor social à profissão e fortalecendo características indenitárias da mesma" (SANTIAGO, 2014, p. 8007).

Em outras palavras, é preciso articular os saberes técnicos, específicos da área, os didáticos e os do pesquisador (MOURA, 2014). Mas, especialmente, compreender que escola, como colocado por Pena (2011), é também, além de espaço para ensino, e campo para pesquisa, um locus de formação docente, onde se constroem as identidades de 
docente, formador, pesquisador e agente transformador, na medida em que ele precisa mobilizar "determinados conhecimentos em sua prática pedagógica, na qual o confronto com situações complexas requer posicionamentos que se apoiam sobre um determinado repertório de conhecimentos produzidos no fazer cotidiano do professor" (PENA, 2011, p. 102). Ou seja, estes podem ser os pesquisadores que produzam um conhecimento mais genuíno e específico sobre a EPT; e, ainda que haja subjetividade na pesquisa, dada especialmente à especificidade do contexto e do professor pesquisador, não sendo fácil distinguir o que é individual do sujeito e o que é influência, resultado de regras e padrões sociais inconscientemente assimilados, Alves-Mazzotti e Gewandszadjder (1998) nos lembra que é possível transpô-la.

Produzir conhecimento, contudo, não é suficiente se este não gera efeitos sobre as suas práticas e nem possam ser compartilhados e considerados nas práticas de outros docentes da EPT. Santiago (2014) nos recorda da importância da socialização do conhecimento entre docentes, fato também colocado por Celani (2002, p. 24), ao dizer que "é preciso educar os professores para que possam se capacitar não só como indivíduos reflexivos em relação à sua prática, mas também como mediadores em um trabalho reflexivo junto a outros professores em suas escolas e regiões". E, se não há tantos espaços para a formação continuada e partilha de conhecimento, os eventos acadêmicos sobre a formação de professores podem se tornar, em nossa opinião, um espaço importante de formação, como podemos perceber ao longo deste trabalho.

\section{Caminhos metodológicos}

Nessa seção, descrevemos primeiramente a natureza da pesquisa, para então apresentar o contexto no qual os documentos analisados foram encontrados e explicar o processo de coleta e análise dos mesmos.

\subsection{Natureza do trabalho}

Esta é uma pesquisa essencialmente qualitativa, apesar de trazer dados numéricos (BROWN \& ROGERS, 2002). Como apontado por Vosgerau e Romanowski (2014), o crescimento desse tipo de pesquisa implica no desenvolvimento de estudos que permitam levantamentos de trabalhos já realizados, identificando temas e assuntos abordados, bem como as oportunidades de produção de novas pesquisas provenientes da identificação de lacunas no campo.

De cunho exploratório, como explica Severino (2007), objetiva levantar e mapear informações sobre um dado objeto a fim de delimitar certo campo de pesquisa. Facilita, assim, através do delineamento do assunto investigado, a descoberta de novos enfoques para o mesmo (PRODANOV \& FREITAS, 2013). As pesquisas exploratórias se dão normalmente através de pesquisas bibliográficas e estudos de caso. No caso da primeira, elaborada a partir de materiais já publicados, como é a proposta do presente trabalho.

Mais especificamente, podemos denominar esta pesquisa como uma metassíntese qualitativa. Esta metodologia, muito comum nos estudos da área da saúde, tem se tornado mais frequente no campo da LA. Alencar e Almouloud (2017), citando Fiorentini (2013), explicam que em uma metassíntese qualitativa seleciona-se trabalhos relacionados a um interesse específico do pesquisador acerca do fenômeno a ser 
investigado, permitindo que este proponha relações entre os trabalhos analisados através de comparações, semelhanças e diferenças.

Assim, pensamos a metassíntese qualitativa como uma ferramenta interessante para agrupar e avaliar os estudos apresentados durante o VII Congresso Latinoamericano de Formação de Professores de Línguas (VII CLAFPL) que tenham como contexto os IFs ou que tenham sido produzidos por docentes dessas instituições. Desta forma, possamos, talvez, compreender quem é esse professor-pesquisador atuante nos IFs e identificar as tendências, recorrências e lacunas tanto nos trabalhos produzidos pelos IFs quanto aqueles produzidos sobre o ensino de línguas nos IFs.

\subsection{Contexto}

Este estudo teve como pano de fundo o VII Congresso Latino-americano de Formação de Professores de Línguas (CLAFPL), realizado entre os dias 11 e 13 de setembro de 2018, na cidade de Belém, no estado do Pará. Organizado pelo grupo de trabalho "Formação de Educadores na Linguística Aplicada", filiado à Associação Nacional de Pós-graduação e Pesquisa em Letras e Linguística (ANPOLL), este evento tem se firmado como um espaço para o debate na área de formação de professores de línguas, especialmente por reunir e acolher pesquisadores, docentes e discentes de universidades e do sistema educacional em geral, na medida em que permite a integração e o intercâmbio entre diferentes grupos de pesquisa da América Latina. De acordo com Miller (2013), periódicos e eventos na área de LA, como o CLAFPL, têm cada vez mais incorporado pesquisas de autoria de professores, mas a autora ressalta que tais trabalhos são ainda por vezes não considerados como pesquisa por alguns.

Desde sua primeira edição, realizada no ano de 2006, em Santa Catarina, esta é a primeira vez que o evento acontece na região norte do Brasil, e teve como tema central "Formação de Professores em Tempos Críticos: Múltiplas Dimensões". Segundo a organização do evento, este contou com aproximadamente 600 participantes que compareceram a quatro conferências, uma mesa-redonda e o tradicional Painel LatinoAmericano. Além disso, em diferentes modalidades, 375 trabalhos foram apresentados em formato de comunicações orais - coordenadas e individuais - e pôsteres, de acordo com o caderno de resumos disponibilizado juntamente com a programação impressa e em meio digital, por pesquisadores brasileiros e estrangeiros. Tais trabalhos foram organizados dentro de vinte temas: Identidades; Dimensões afetivas; Crenças; Educação inclusiva; Educação bilíngue; Motivação; Abordagens reflexivas; Perspectivas críticas; Análise do discurso; Pedagogia de línguas; Multiletramentos; Tecnologias digitais; Avaliação; Currículos e Projetos pedagógicos; Estágios curriculares; Planejamento do trabalho docente; Comunidades de prática; Projetos de extensão e Parcerias universidade-escola; Desenvolvimento profissional do formador; e Políticas linguísticas. dados.

A seguir, apresentamos mais detalhadamente o processo de coleta e análise dos

\subsection{Descrição da coleta de dados}

O levantamento de dados se deu através da análise do caderno de resumos publicado online pela organização do evento em seu website oficial, e conferido através do caderno impresso entregue durante o evento juntamente com sua errata. A escolha 
pelo uso caderno em detrimento dos anais se deu devido ao fato dos anais não englobarem todos os trabalhos apresentados no evento, característica esperada na produção deste gênero textual.

Os trabalhos apresentados no evento foram organizados entre comunicações coordenadas, nas quais um pesquisador doutor propôs e organizou a discussão de um tema e convidou de três a quatro pesquisadores para apresentarem seus trabalhos dentro desta perspectiva, tendo todos submetido seus trabalhos em conjunto; comunicações individuais, nas quais os participantes foram agrupados de acordo com a proximidade dos temas que apresentariam; e a seção de pôsteres. Apesar das diferenças no formato de apresentação, todos os resumos enviados deveriam conter título, apresentar os objetivos, métodos, resultados e conclusões, de modo que os leitores não necessitassem consultar o trabalho original. Todos os títulos eram seguidos pelos nomes dos autores e das instituições as quais estavam filiados, com exceção dos pôsteres, que continham apenas os nomes dos autores.

Foram feitas basicamente duas leituras para a recuperação dos textos adicionados à pesquisa:

- Leitura de reconhecimento: rápida e objetiva, para identificação dos textos efetivamente produzidos por docentes dos IFs, como base na indicação de vinculação feita junto à autoria;

- Leitura seletiva: integral, de todos os resumos, a fim de delimitar quais textos tinham IFs como contexto de pesquisa;

Após a leitura dos 375 resumos disponíveis e seleção de 39 entre eles, estes foram novamente lidos e agrupados em tabela do programa Microsof Office Excel a fim de comparar autores, objetivos, contexto de produção, e a língua envolvida. Para completar, buscamos o currículo de todos os autores dos textos selecionados na plataforma Lattes, disponibilizada pela Capes. Dessa forma foi possível identificar sua titulação e instituição a qual se conveniou, por motivo da pesquisa ou de sua atuação profissional.

Por fim, todos os dados existentes nas tabelas foram relidos, agrupados e reagrupados por semelhança, na tentativa de responder à questão norteadora da pesquisa, como indicado por Vosgerau e Romanowski (2014).

\section{Análise e discussão}

Após a leitura dos 375 resumos $^{2}$ dos trabalhos apresentados no evento, identificamos que apenas 39 destes foram produzidos por professores de Institutos Federais - distribuídos nos formatos de comunicação oral coordenada, individual e pôster, o que equivale a pouco mais de $10 \%$ do total de trabalhos apresentados no evento, como podemos ver no gráfico a seguir (Graf.1).

\footnotetext{
${ }^{2}$ Ressaltamos que apesar da instrução e regras definidas pelo comitê científico do evento para a elaboração dos resumos, nem todos respeitaram as prescrições, deixando, por vezes, de mencionar ou definir claramente o aporte teórico, ou o contexto da pesquisa e seus participantes. Assim, há a possibilidade de outros trabalhos que tratem do contexto dos IFs terem sido apresentados, mas que não puderam ser aqui identificados.
} 


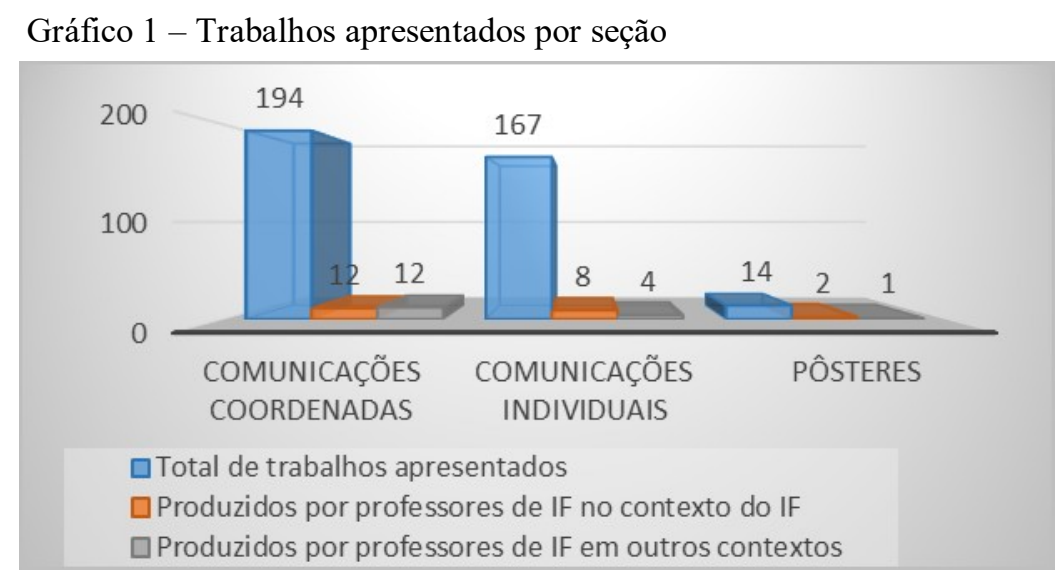

Fonte: Elaborado pelas autoras.

Com base nos dados apresentados no gráfico (Graf.1), poderíamos dizer que há baixa representatividade não só dos institutos como campo para pesquisa, mas também como produtor de conhecimento na área de formação de professores e ensino de línguas, o que vai ao encontro do que foi posto por Pena (2016) e Santiago (2014) sobre a incidência de pesquisas no contexto da EPT. Contudo, para fazer tal afirmação com segurança seriam necessários outros estudos similares, como por exemplo, revisando e comparando esses dados com outras edições do CLAFPL e, até mesmo, outros eventos a nível nacional como o Congresso Brasileiro de Linguística Aplicada (CBLA). Ainda assim, com base nos números apresentados no gráfico acima, nos intriga qual seria a razão destes valores. Talvez tal fato esteja relacionado à dificuldade em conciliar as atividades de docência com as de pesquisa (BORTONI-RICARDO, 2008) ou à uma cultura de produção acadêmico-científica no campo da docência na EPT (GARIGLIO \& BURNIER, 2012) ainda incipiente. Contudo, assim como posto por Gariglio e Burnier (2012) e Miller (2013), através da interação professores-pesquisadores-alunos, tanto em sala de aula quanto em eventos acadêmicos, é possível ir aos poucos desenvolvendo essa cultura de investigação da e na prática docente, com pesquisas colaborativas, pesquisa ação e prática exploratória.

Apesar da aparente baixa representatividade, vale ressaltar que neste grupo de pesquisas identificamos representantes de institutos de diversas regiões brasileiras, a saber: Centro-oeste (IFB, IFG e IFMS); Nordeste (IFAL, IFBA e IFRN); Norte (IFAM, IFPA, IFRR e IFTO); Sudeste (CEFET-MG, CEFET-RJ, IFMG, IFSP, IFRJ e Colégio Pedro $\mathrm{II}^{3}$ ); e Sul (IFC, IFPR e IFSC). Além disso, se considerarmos a distribuição destes institutos no Brasil (Fig.1), poderíamos dizer que estes trabalhos representam uma parcela significativa do número de institutos existentes, cada um com suas particularidades. Os destaques em número de professores de IFs participantes se dão para as regiões Sudeste, com 15, a Norte, com 12 e a Centro-oeste, com 8. Sul e Nordeste contaram com apenas 3 participantes cada. Dada a maior concentração de institutos no Sudeste, e sua tradição acadêmica, já esperávamos por esse destaque. Contudo, talvez a localização do evento possa ter sido fator decisivo para a participação das outras regiões. Não obstante, neste montante de trabalhos, do total dos 45

\footnotetext{
${ }^{3}$ A inclusão do Colégio Pedro II neste trabalho levou em consideração a Lei 12.677 de 25 de junho de 2012 que o equipara aos Institutos Federais, passando a oferecer também cursos técnicos no Ensino Médio Integrado e Proeja. Fonte: (website institucional) www.cp2.g12.br
} 
pesquisadores participantes (sendo 6 destes como segundo autores), todos ${ }^{4}$ atuam como professores de IFs, salvo dois pesquisadores ligados à universidades que fizeram o trabalho em parceria com outros professores.

No que tange a formação acadêmica desses pesquisadores, diferente do que observa Pena (2016) sobre os docentes das disciplinas técnicas, ao afirmar que grande parte possui mestrado e doutorado em suas áreas de conhecimento especifico, podendo ingressar no magistério com pouca referência pedagógica sistematizada, este grupo de professores-pesquisadores aqui analisados, em especial, tem formação pedagógica e continuada com foco no ensino propedêutico dada à sua área de atuação, como colocado por Oliveira, Sales e Silva (2017). São professores licenciados em sua área de ensino, a linguagem, e que tem se dedicado aos estudos stricto e lato sensu, como podemos notar no gráfico a seguir (Graf.2).

Gráfico 2 - Formação acadêmica dos autores.

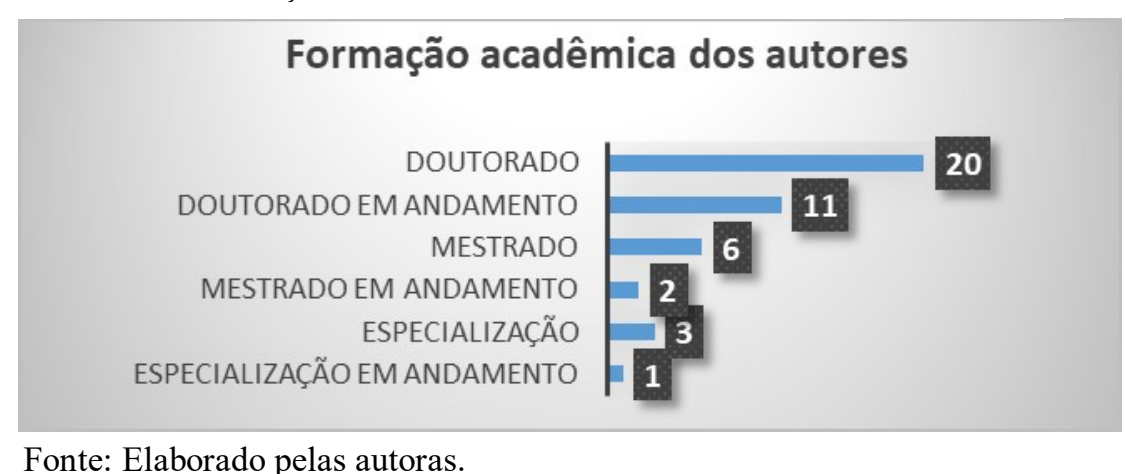

De acordo com o gráfico (Graf.2), todos esses docentes têm buscado formação continuada. Entendemos que esse perfil profissional, que se dedicou à formação continuada, possa ter influenciado a trajetória desses docentes, que investem também em pesquisas, tornando-se professores-pesquisadores, que Santiago (2014) entende como um investimento que visa enriquecer suas práticas pedagógicas.

As pesquisas apresentadas desenvolvidas no contexto do IF tiveram como pano de fundo as salas de aula das disciplinas de línguas no ensino técnico integrado ao médio e dos cursos de extensão oferecidos nos campi. Já as pesquisas realizadas fora do contexto do IF, se voltaram para escola regular, ensino fundamental I e II, curso EAD, disciplina de atendimento especial no ensino superior, documentos (BNNC e Lei $11161 / 2005)$ e na formação continuada e inicial de professores. Notamos que diversos trabalhos que não tinham relação direta com os IFs faziam parte das pesquisas de doutoramento dos docentes.

Após a leitura dos resumos, percebemos que os trabalhos abrangeram a maioria dos eixos temáticos definidos no evento, se encaixando, por vezes, em mais de um. No geral, estes trabalhos trazem relatos de experiências, como podemos notar abaixo:

- No eixo sobre inclusão, retratam a inclusão de alunos com necessidades educacionais especificas na EPT, compartilham relato do ensino e de qual a

\footnotetext{
${ }^{4}$ Ao submeterem seus trabalhos, os participantes do VII CLAFPL deveriam indicar a qual instituição estavam vinculados. Ressaltamos que diversos professores de IF se identificaram como tal, outros a universidades. Como explicado na seção de metodologia deste trabalho, verificamos o currículo apenas dos trabalhos selecionados e dos participantes que indicaram seu vínculo com os IFs. Assim, é possível que haja outros pesquisadores vinculados a IFs que não tenham sido identificados.
} 
formação disponibilizada ao professor de línguas, mais especificamente de língua Portuguesa, para o ensino desta a alunos surdos;

- Pesquisas que envolvem as dimensões afetivas no processo de ensinoaprendizagem e relatam o sofrimento dos professores e emoções de alunos e professores em um projeto de extensão;

- Abordagens críticas e perspectivas críticas no ensino, com reflexão sobre o processo de escrita acadêmica, propostas de ciclos de tarefas, relatos de intervenções com letramento crítico através da multimodalidade na perspectiva dos multiletramentos, e experiência com curso de letramento em avaliação e com o uso de autoavaliação na formação discente;

- Identidade do professor sobre ensinar e ser pesquisador na pós-graduação;

- Desenvolvimento profissional com foco na formação continuada, sobre o valor do saber do professor de português nesses cursos, a tomada de consciência sobre a importância da reflexão para o agir e a importância da prática da professora formadora que atua na formação continuada;

- No campo de projetos de extensão e parcerias universidade-escola, há relato sobre o ensino de português para estrangeiros, propostas pedagógicas e proposta de curso de formação inicial e continuada para professores;

- Relato de experiências na sala de aula sobre abordagem comunicativa, uso de séries de TV, diálogos, e no campo da tecnologia com o uso das Tecnologias Digitais da Informação e Comunicação (TDICS), como Whatsapp.

Com base nos temas dos trabalhos, nos parece que estes pesquisadores já perceberam o potencial exploratório da sala de aula, além de encontrarem-se em um processo de legitimação do conhecimento docente (MACIEL, 2013), pois ninguém melhor para conhecer e refletir sobre as experiências e conflitos que emergem no cotidiano da sala de aula e instituição do que o próprio docente. Assim como exposto por Celani (2002) e Santiago (2014), essas pesquisas aparentam tentar refletir sobre e/ou responder questões colocadas pelos próprios docentes durante sua prática pedagógica, levando-os a aprender à medida que pesquisam e ensinam, ou seja, assumindo a responsabilidade por tentar compreender e buscar alternativas para as questões que enfrentam em sua atuação (MOURA, 2014).

Já fora do âmbito da sala de aula, há um trabalho que investiga os sentidos de enunciados políticos através da análise do discurso, e outros dois, no campo das políticas públicas, sobre as consequências da revogação da Lei 11161/2005, que trata do ensino do espanhol, para a formação dos professores de língua espanhola, e o ensino desta língua em uma outra instituição federal. Há também uma discussão sobre o que a Base Nacional Comum Curricular (BNCC) traz sobre o ensino de literatura em língua espanhola, mas no contexto da escola regular. Apesar de não discutirem questões referentes exclusivamente à sala de aula, ao conhecerem e dominarem certo conteúdo, poderão se apropriar desse conhecimento e usá-lo a seu favor (MOURA, 2014), seja para o ensino na sala de aula ou para discussões a nível institucional.

Arruda (2014) nos lembra da necessidade de mais estudos que evidenciem o positivo, o que tem dado certo, especialmente na escola pública, se quisermos advogar por uma mudança paradigmática no ensino de línguas estrangeiras, bem como de língua portuguesa. E, é justamente isso que percebemos neste evento, muitos relatos de experiências e práticas de sucesso. Outro ponto, que consideramos mais importante e positivo, é a presença da construção de uma identidade de professores-pesquisadores, 
reflexivos e conscientes sobre sua prática e formação continuada, na medida em que se nota que os próprios docentes têm tentado compreender e buscar alternativas para as questões que enfrentam em sua prática (MOURA, 2014). Além disso, tais pesquisas podem contribuir tanto para a atuação quanto para a formação do próprio pesquisador e de outros profissionais de EPT (SANTIAGO, 2014).

Contudo, ainda sentimos a necessidade de saber mais sobre os desafios enfrentados na sala de aula, especialmente no que concerne a integração entre o ensino das línguas e o conteúdo específico da parte técnica, como indicado por Pena (2016) sobre a dificuldade de articulação entre esses saberes. Pena (2016) nos fala ainda das pesquisas que já mostraram as especificidades que devem ser levadas em consideração para a docência no contexto da EPT, pois estas trazem diversos desafios para a atuação do docente. Assim, acreditamos que os desafios enfrentados por esse sujeito, no âmbito do ensino, pesquisa e extensão devem ser pesquisados, compartilhados, para então serem discutidos no âmbito dos eventos acadêmicos, cursos de formação, levados até os grupos de trabalho com foco no desenvolvimento de políticas para a Rede Federal de ensino.

\section{Considerações Finais}

Sabemos da importância de se conhecer quem são os docentes da EPT e como estes atuam (PENA, 2011) e também das especificidades desse contexto (PENA, 2016). Conhecer sobre como os processos que circundam a produção de conhecimento por parte do professor-pesquisador e que tipo de conhecimento é esse também tem se mostrado importante (MARCELO, 1998 apud PENA, 2011).

A busca por mais compreensão sobre esse contexto de ensino e pesquisa é justificável, pois como disse Celani (2002, p.32), citando Fullan (1996) "só quando maior clareza e coerência forem conseguidas nas mentes da maioria dos professores, teremos alguma chance de êxito". É preciso entender, porém, que tais pesquisas não podem ser encaradas como um produto, mas um processo (MILLER, 2013). Não trazem verdades absolutas, mas olhares possíveis para esse distinto contexto, que pode ser ainda mais específico a depender das características inerentes a cada campus dos IFs e respectivas salas de aula, bem como da subjetividade do professor-pesquisador.

Essa questão, no entanto, não pode ser fator limitante para as pesquisas e divulgação científica através não só da participação em eventos, mas também em publicações acadêmicas. Já temos notado o desenvolvimento de uma identidade de professor-pesquisador na área da LA, que pode ser percebida na participação dos docentes no VII CLAFPL, alguns destes em destaque, tendo sua presença cativa em outros eventos da área também no ano de 2018. Cria-se aí também uma oportunidade de troca, uma comunidade de prática.

E, se a docência na EPT é considerada por alguns pesquisadores como um oficio feito de saberes, é vital que haja incentivo para que os professores de línguas invistam em sua formação continuada - fator que pode ter sido significativo para a participação dos docentes que apresentaram suas pesquisas no VII CLAFPL - e continuem a desenvolver pesquisas e se engajar nos eventos acadêmicos, valorizando seu fazer docente e seu contexto de trabalho. Buscando, não só, a melhoria de suas práticas, mas também para os IFs como um todo, contribuindo para sua formação em serviço, como exemplo para futuros docentes da EPT e para seus alunos. 
Consideramos, assim, que as teorias sobre o ensino na EPT podem estar sendo concebidas na prática e reflexões teóricas através das pesquisas destes e de muitos outros professores-pesquisadores. Acreditamos, igualmente, na importância que esse e outros eventos possam ter para socialização desse conhecimento e para o incentivo à formação de professores-pesquisadores interessados e engajados, também, na mediação junto a outros docentes. Assim, com base no exposto, sugerimos que mais pesquisas investiguem o perfil do professor de língua materna e línguas estrangeiras atuantes na Rede Federal, seu contexto e conflitos, suas abordagens, especialmente sobre a integração entre o conhecimento sobre línguas e EPT e as questões de formação a nível institucional. Dessa forma, ao conhecermos e compartilharmos o conhecimento produzido pelos professores-pesquisadores da EPT, possamos melhor compreender e refletir sobre ações em nível de formação inicial, continuada e institucional a fim de não só valorizar a área das linguagens, mas também mais investimentos para tal.

\section{Referências}

ALENCAR, E.S.; ALMOULOUD, S.A. A metodologia de pesquisa: metassíntese qualitativa. Revista Reflexão e Ação, Santa Cruz do Sul, v. 25, n. 3, p. 204-220, Set./Dez. 2017.

ALVES-MAZZOTTI, A.J.; GEWANDSZADJDER, F.O. O método nas ciências naturais e sociais: pesquisa quantitativa e qualitativa. São Paulo: Pioneira, 1998.

ANDRADE, M.C.F.; SOUZA, A.C.R. A formação de professores para o ensino profissional no Brasil: a construção de um caminho. Anais do III Colóquio NacionalEixo Temático III - Formação de professores para a educação profissional. Natal/RN: Instituto Federal de Educação, Ciência e Tecnologia do Rio Grande do Norte, 2015. p. $1-10$.

ANDRÉ, M. Pesquisa em educação: questões de teoria e métodos. Educação Tecnológica, v.10, n.1, p. 29-35, jan./jun., 2005.

ARCHANJO, R. Linguística Aplicada: uma identidade construída nos CBLA. Revista Brasileira de Linguística Aplicada, Belo Horizonte, v. 11, n. 3, p. 609-632, 2011

ARRUDA, C.F.B. Experiências bem-sucedidas de inglês na escola pública: a relação entre agência e propiciamento. In: MICCOLI, L. (Org.) Pesquisa experiencial em contextos de aprendizagem: uma abordagem em evolução. Campinas, SP: Pontes Editores, 2014.p.371-406.

BORTONI-RICARDO, S.M. O professor pesquisador: introdução à pesquisa qualitativa. São Paulo: Parábola Editorial, 2008.

BRASIL. Relatório de Auditoria - Acórdão no 506/2013/TCU. Brasília, DF, 2013. 
BRASIL, Ministério da Educação. Instituições da Rede Federal. Disponível em: http://portal.mec.gov.br/rede-federal-inicial/instituicoes. Acesso em: 29/06/2020

BRASIL, Ministério da Educação. Educação Profissional e Tecnológica (EPT). Disponível em: http://portal.mec.gov.br/educacao-profissional-e-tecnologica-ept. Acesso em: $29 / 06 / 2020$

BROWN, J.D.; RODGERS, T. S. Doing Second Language Research. Oxford: Oxford University Press, 2002.

CELANI, M.A.A. Um programa de formação contínua. In: CELANI, Maria Antonieta Alba (Org). Professores e formadores em mudanças: relato de um processo de reflexão e transformação da prática docente. Campinas: Mercado das Letras, 2002, p. 19-36.

FREIRE, P. Pedagogia da autonomia: saberes necessários à prática educativa. São Paulo: Paz e Terra, 1996.

GARIGLIO, J.A.; BURNIER, S. Os professores da educação profissional: saberes e práticas. Cadernos de pesquisa. v. 44, n.154, p.934-959, out/dez, 2014.

GARIGLIO, J.A.; BURNIER, S. Saberes da docência na Educação profissional e tecnológica: um estudo sobre o olhar dos professores. Educação em Revista, v.28, n.01, p.211-236, mar, 2012.

GIMENEZ, T. Formação de professores de línguas no Brasil: avanços e desafios. In: SANTOS, L.I.S.; SILVA, K.A. (Orgs.). Linguagem, ciência e ensino: desafios regionais e globais. Campinas, SP: Pontes Editores, 2013.p.41-54.

JUNIOR, W.O. A formação do professor para a educação profissional de nível médio: tensões e (in)tenções. In: PARANÁ. Secretaria de Estado da Educação. Superintendência de Educação. $O$ professor PDE e os desafios da escola pública paranaense: produção didático-pedagógica, 2009. v.2. Curitiba: SEED/PR., 2012. (Cadernos PDE).

MACIEL, R.F. Políticas linguísticas, conhecimento local e formação de professores de línguas. In: NICOLAIDES, C.; SILVA, K.A.; TÍLIO, R.; HILSDORF, C.R. (Orgs.) Política e políticas linguísticas. Campinas, SP: Pontes Editores, 2013.p.237-261.

MILLER, I.K. Formação de professores de línguas: da eficiência à reflexão crítica e ética. In: MOITA LOPES, L. P. (Org.) Linguística Aplicada na Modernidade Recente. São Paulo, Parábola, 2013. p.99-121.

MOITA LOPES, L.P. Linguística aplicada e vida contemporânea: problematizações dos construtos que tem orientado a pesquisa. In: MOITA LOPES, L.P. (Org.). Por uma linguística aplicada indisciplinar. São Paulo: Parábola, 2006. p.85-105. 
MOURA, D.H. Trabalho e formação docente na educação profissional. Curitiba, PR: Instituto Federal do Paraná, 2014. (Coleção formação pedagógica; v. 3).

MOURA, D.H. A formação de docentes para a educação profissional e tecnológica. Revista Brasileira da Educação Profissional e Tecnológica, 2008. p.23-38

OLIVEIRA, R. de. S.; SALES, M.A.; SILVA, A.L.G. Professor por acaso? A docência nos Institutos Federais. Revista Profissão Docente. v. 7, n.37, p.5-16, ago./dez., 2017. PENA, G.A.C. Prática docente na educação profissional e tecnológica: os conhecimentos que subsidiam os professores decursos técnicos. Formação Docente, v. 09, n. 15, p. 79-94, ago./dez. 2016.

PENA, G.A.C. Formação docente e aprendizagem da docência: um olhar sobre a educação Profissional. Educação em Perspectiva, v. 2, n. 1, p. 98-118, jan./jun. 2011.

PRODANOV, C.C; FREITAS, E.C. Metodologia do trabalho científico: métodos e técnicas da pesquisa e do trabalho acadêmico. 2. ed. Novo Hamburgo, RS: Feevale, 2013.

SANTIAGO, R.V. O professor da educação profissional técnica e tecnológica: identidade e formação. Anais do II Congresso Nacional de Formação de Professores e XII Congresso Estadual Paulista sobre Formação de Educadores. Aguas de Lindóia, SP: Universidade Estadual Paulista, p.7997-8009, 2014.

SEVERINO, A.J. Metodologia do trabalho científico. 23. ed. São Paulo: Cortez, 2007.

VOSGERAU, D.S.R.; ROMANOWSKI, J.P. Estudos de revisão: implicações conceituais e metodológicas. Rev. Diálogo Educacional, v. 14, n. 41, p. 165-189, jan./abr. 2014.

Recebido em 29 de maio de 2020

Aceito em 08 de junho de 2020 